\title{
Management StRategies to Conserve MARINE BIODVERSITY
}

\author{
By James A. Bohnsack and Jerald S. Ault
}

\begin{abstract}
$\mathrm{M}$ ARINE BIODIVERSITY is increasingly threatened by habitat destruction. environmental changes, and overexploitation. Preventing reductions in biodiversity and promoting sustainable resource use requires new management strategies, more effective education, and strong research. There is a need to switch to less destructive and wasteful fishing methods to protect critical and sensitive habitats from development and overexploitation. Marine reserves, areas permanently protected from all extractive uses, are gaining widespread attention as an innovative tool for conserving biodiversity while maintaining healthy sustainable fisheries. Effective use of marine reserves requires the integration of scientific disciplines in fisheries, oceanography, computer science, system analysis, ecology. genetics. social science. and conservation. Marine reserves are an essential element of the draft management plan for the Florida Keys National Marine Sanctuary. The Sanctuary presents a unique opportunity to elucidate the relative impacts of fisheries exploitation and oceanographic processes in determining the biodiversity and abundance of reef organisms. Cooperative academic and governmental research will test critical scientific hypotheses in order to improve the state-of-the-art in marine resource management.
\end{abstract}

\section{Introduction}

Biodiversity is the variety of living organisms and their habitats: the structure, composition. dynamics, and function of living systems acquired over millions of years of evolution. Marine biodiversity is extremely rich but is poorly understood and has only recently become the subject of conservation concerns (Norse. 1993). Biodiversity refers to the spatial organization of plants and ani-

James A. Bohnsack. National Marine Fisheries Service. SEFC. Mami Laboratory. 75 Virginia Beach Dr.. Miami. FL 33149. USA. Jarald S. Ault. Universty of Miami. Rosenstiel School of Marme and Atmospheric Science, Division of Marine Biology and Fishernes, 4600 Rickenhacker Causeway. Miami, FL 331+9, USA. mals in a hierarchy at the genetic, organism. population, species, community, ecosystem, and seascape levels (Hughes and Noss, 1992: Norse. 1993). Major threats to biodiversity are habitat destruction, environmental changes, and overfishing (Upton, 1992). Losses of biodiversity at the genetic and species levels are of special concern because they are permanent.

This article focuses on management strategies that protect marine biodiversity and promote sustainable resource use. These strategies are evaluated in terms of their ability to fultill three criteria: economic efficiency, Hexibility, and ease of implementation. The emphasis of current fishery management practice is on fishing. which includes all extractive harvesting activities. Fishing is socially and economically important, but if done improperly or to excess fishing can threaten biodiversity (Huntsman, 1994). It is also important to protect water quality and habitat from other destructive human activities that include poor land use practices and pollution. especially the release of excess sediments, nutrients, sewage, and toxic materials. Other activities that can threaten marine biodiversity include oil and gas extraction, vessel traffic. and release of diseases and parasites from mariculture.

In this paper we describe a management strategy to conserve biodiversity: a strategy incorporating impacts on habitat, and the biological, social and economic factors of overfishing. We propose new management tools including use of habitat restoration and marine reserves to maintain biodiversity and sustain fisheries. Finally, we review an application in the Florida Keys National Marine Sanctuary in the context of some testable scientific hypotheses.

\section{Habitat Impacts}

Some fishing methods destroy habitat and biodiversity. Damage can be reduced by using less destructive and wasteful fishing methods, protecting critical habitats from development. and setting some areas aside as marine fishery reserves. In the United States, many destructive fishing practices
$F_{\text {ishing is socially }}$ and economically important, but if done improperly or to excess fishing can threaten biodiversity. 
have been prevented, eliminated, or closely regulated. These include the use of dynamite, muro ami fishing (Öhman et al., 1993), and chemicals such as bleach and cyanide. Bottom trawling and bottom-set nets can damage coral reefs and other habitats. However, research and management are still needed in cases such as mechanical damage to oyster beds by hydraulic-powered patent tongs (Rothschild et al., 1994), and the cumulative impacts of fishing gears on critical habitats.

\section{Overfishing}

Most fisheries depend on harvesting wild populations whose productivity is derived from biodiversity. Although it was once believed that fishing could not harm wild populations, the collapse of major fisheries shows that most, if not all, marine resources are exhaustible (Knauss. 1992: Hutchings and Myers, 1994). Overfishing is a major threat to biodiversity because it depletes resources that can lead to loss of genetic integrity, local populations, and even species (Boehlert. 1996, this issue). Wasteful fishing catches unwanted organisms (bycatch), individuals that are too small (growth overfishing). and too many adults that can result in recruitment failure from decreased population egg production (recruitment overfishing). Over time, fishing can selectively remove animals with genetically superior traits (genetic overfishing) (PDT, 1990); starting with the most vulnerable species (serial overfishing) (Munro and Williams, 1985); and particularly important "keystone" species. which can disrupt community structure and function (ecosystem overfishing). Overfishing involves a nexus of complex biological, social, and economic factors.

\section{Biological Factors}

Most exploited marine species have bipartite life cycles; pelagic (open water) larvae followed by demersal (bottom) juvenile and adult life stages. During the pelagic stage. planktonic eggs and larvae are dispersed by ocean currents over periods ranging from days to months before assuming a demersal existence. Although some species settle directly onto adult habitats, others may use different habitats before assuming an adult existence due to ontogenic or environmental factors. Many demersal organisms, particularly reef species, tend to be relatively sedentary, showing strong site fidelity and limited geographic movement (Sale, 1980; Beinssen, 1988; PDT, 1990). Migratory species may use different habitats depending on age and season. Pelagic species. such as tuna and billfishes, spend their entire life cycle in open water environments.

Fecundity typically increases exponentially with body size (Ault and Olson, 1996). For example. the gonads of one female red snapper at $61 \mathrm{~cm}$ total length has the same weight as 212 females at $42 \mathrm{~cm}$ (Grimes, 1987). Also, the larger gonad has increased convolutions meaning greater surface area for ova production. Thus, on average, a few older individuals may account for more total reproductive output than many younger individuals.

Recruitment success is in general poorly correlated with adult stock size (Rothschild, 1986: Underwood and Fairweather, 1989). Abundant stock and reproductive output may result in poor recruitment owing to egg and larval mortality caused by physical and biological factors (Rothschild, 1986). For example, temperatures may be too cold or too hot, and winds and currents may sweep larvae into areas unsuitable for settlement. Fertilization rates, food availability, predator presence, and other factors may vary greatly. Low population reproductive output decreases the probability of good recruitment (Goodyear, 1989). Normally, millions of eggs produced may result in only tens of survivors. As a result, the annual supply of new recruits (year class strength) may vary by several orders of magnitude (Doherty and Williams, 1988).

Habitat suitability and availability may limit recruitment, but recruitment variability is most likely to limit adult abundance for many species (Doherty and Williams, 1988; Hughes, 1990; Sale, 1991). Although postsettlement survival is higher, subsequent mortality can still affect community structure and population abundance through competition, predation, parasitism, disease, and fishing mortality. The last factor can exceed natural mortality for many exploited species (Bohnsack, 1994).

High recruitment variability tends to result in specific traits to ensure species survival (Murphy, 1968). In reef species, for example, such traits include slow growth, large size, delayed onset of first reproduction, multiple spawning, and long lives (Bohnsack, 1994). One successful strategy for fishes under these conditions is protogynous hermaphroditism. in which fishes change sex from female to male as they age and grow larger.

These characteristics make many reef species especially vulnerable to fishing, which targets and eliminates larger individuals because of their greater economic and sport value. Larger animals may be exceptionally vulnerable because of their more aggressive behavior (Thompson and Munro. 1974; Nelson and Soulé, 1987). For protogynous hermaphrodites, excessive size-selective exploitation can promote "juvenesence" by truncating the stock's older age classes, resulting in too few males to adequately fertilize eggs (Bannerot et al., 1987). For other species, few individuals may survive to mature, and the number of spawning chances may be greatly reduced. Some species can be easily located and fished even when severely depleted because of their predictable behavior and geographically restricted habitats.

\section{Social and Economic Factors}

Overfishing results from a suite of complex social and economic factors that are difficult to man- 
age because of poor education, lack of enforcement, strong cultural traditions, and political factors (Waters, 1991; Ludwig et al., 1993; Rosenberg et al., 1993). Education of stakeholders and managers is important to successful dealings with many of these issues. People often have unrealistic perceptions about resource productivity and sustainability and tend to be skeptical of management and conservation efforts.

The most widely acknowledged factor causing overfishing is the "tragedy of the commons" (Hardin, 1968), where open access fisheries encourage competition and discourage conservation. To increase individual shares of the available resource, people inevitably fish more, producing declines in total net revenues. When giving something up is most likely to directly benefit competitors, there is little incentive to conserve resources. The problem can become exacerbated when a species value increases as the stock declines, as happened with fur seals and Atlantic bluefin tuna. Overfishing can also result from interactions between the environment, animal behavior, and fishing operations. For example, reef fish catch rates may remain high, giving the perception of high stock abundance, buoyed by the fishery continuing to find and deplete new unexploited reefs, even though the unit stock is overfished. Overfishing can also occur for pelagic schooling species (e.g., sardines and anchovies) where environmental conditions concentrate an otherwise depleted stock into a smaller area, making the remaining stock more vulnerable to fishing effort. Often political pressures for demonstrating an absolute certainty of overexploitation deters managers from taking appropriate action. It is also very difficult to get the conservation community as concerned about fishes and invertebrates as they seem to be about other "warm and fuzzy" animals (McClanahan, 1989). Marine mammals and birds are perceived as cuddly and cute, whereas fishes are considered cold, slimy, and ugly.

It is especially difficult for managers to counter the "people versus critters" argument. Overfished stocks produce economic stresses. and reductions in fishing effort would only create further hardships (Ludwig et al., 1993). Instead of reducing take. managers often allow the same or increased catches, further reducing stock productive capacity and exacerbating economic hardships. When management actions are taken. they tend to be minimal instead of decisive. The time between gathering the necessary data and taking action allows the resource to decline further. Actions that could have been effective early are no longer sufficient. Continuation of this process results in the resource declining to where "economic rent" approaches or drops below zero. Finally, when (and if) resources begin to recover, fishers exert great pressure to prematurely increase harvests before the stock has fully recovered. If recovery does occur, the cycle of overfishing recurs.

In general, managers tend to be too optimistic and risk prone because the bases for their actions are founded on unreliable assessment methods, imprecise estimates and hence predictions, coupled with extreme uncertainty concerning recruitment. It is often assumed (or hoped) that a good year class will eventually arrive and make unpopular actions unnecessary. Thus, while the economic and social forces leading to overfishing are generally well understood (Ludwig et al., 1993: Hutchings and Myers, 1994), and possible remedies have been described (Rosenberg et al., 1993), fisheries still collapse.

\section{Fishery Management}

The usual objective of fishery management is to achieve an "optimum yield" based on weighted objective function that includes biological, economic, and social factors. But management plans usually treat single species and ignore impacts on biodiversity, environmental variation, and the interactions between species, habitat, and fisheries (National Research Council, 1994). Rarely are effects of fishing on genetic quality of stocks considered. although size selectivity may take the fastest growing and the genetically most "fit" animals first (Bergh and Getz, 1989).

The paradigm of fisheries regulation is to prevent undersized fish from being caught or to allow a sufficient number of fishes to escape harvest to ensure sufficient adult spawning stock to maintain high average recruitment levels. The two principal forms of regulation are to control the size of organisms taken and the amount of harvesting effort applied. Specific regulations include size limits. bag limits. quotas. limited entry, fishing seasons. area closures, and gear restrictions, such as larger mesh sizes on trawls, bycatch reduction devices in nets, or larger hook sizes (Munro and Williams, 1985).

Many traditional management measures fail to reduce fishing pressure and protect biodiversity because of high release mortality, inadequate models, inability to control fishing effort, poor compliance, and unenforced or unenforceable regulations. Some measures demand accurate and continuous data acquisition, which can be difficult to obtain, and intensive analyses, which are vulnerable to cheating or misrepresentation. Monitoring may be impractical if there are a large number of fishing operations, many species in the fishery, and several different kinds of fishing gears in use. Traditional techniques may not effectively be equipped to deal with serial overfishing, genetic selection. bycatch, and release mortality.

The need to balance and integrate the two principal approaches to stock management, based on fisheries regulation and understanding the environment. has increased over the last decade resulting
It is especially

difficult for managers

to counter the "peo-

ple versus critters"

argument. 
in pervasive recommendations to move from single species to ecosystem management (National Research Council, 1994). However, there are obviously costs associated with the paradigm shift. Ecosystem management requires a better understanding of the coupling, function, and dynamics of organisms, their habitats, and better fishery-independent monitoring of communities and habitat conditions. The many failures of fisheries management to protect biodiversity and maintain sustainable fisheries also strongly emphasize the need for new and innovative ideas and solutions. Besides reducing fishing, two promising long-term alternatives are habitat restoration and establishment of marine reserves; both require colonization of habitats by natural processes. Habitat restoration has great potential in damaged environments, but further research on its effectiveness is clearly needed (Bohnsack, 1996). Except under unique circumstances, deployment of artificial reefs or release of hatchery-raised organisms has less potential for restoring biodiversity and rebuilding sustainable fishery productivity. In addition, introduction of exotic organisms is not recommended because of unpredictable consequences and the general inability to correct mistakes. Designating certain marine areas as "protected"-usually by officially naming them "sanctuaries" or "reserves"-is a revolutionary resource-management tool used in mitigating habitat degradation and overfishing. Marine reserves are an essential element in ecosystem management and offer considerable potential for protecting and restoring marine biodiversity.

\section{Marine Reserves}

There is widespread interest in the use of marine reserves. In reserves, access to critical habitats is permanently restricted. As a result, re-

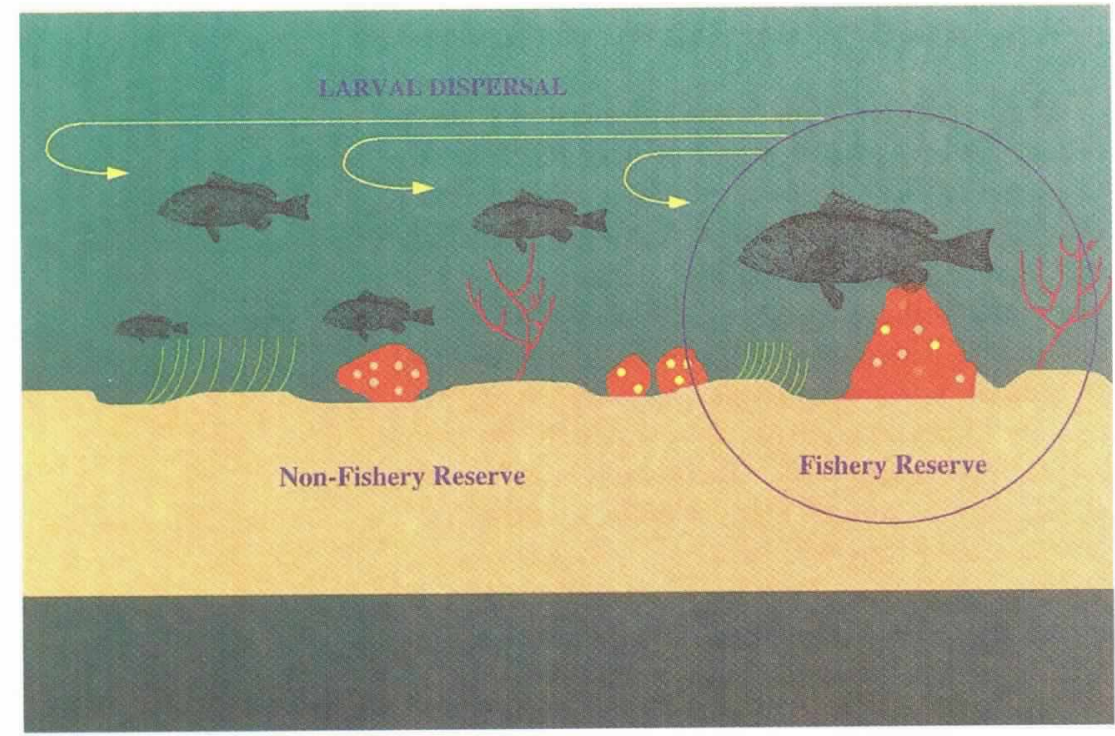

Fig. 1: Conceptual model showing how marine reserves can protect spawning stocks and disperse larvae into surrounding areas. serves have more natural species composition, age structure, spawning potential, and genetic variability. Because they can aid efforts to conserve biodiversity and environmental quality, marine reserves may help maintain sustainable fisheries by naturally exporting biomass and larvae to the surrounding areas. Protected areas reduce conflict by limiting the number of management objectives in an area and are appealing because of their simplicity (Roberts and Polunin, 1993).

Marine reserves recreate natural refuges that were too deep, remote, hard to locate, or unfishable in the past (Dugan and Davis, 1993). Such refuges have disappeared or become less effective because of increased fishing effort and improved technology (Epperly and Dodril, 1995). Because most demersal organisms, especially postsettlement fishes, are rather sedentary and strongly site specific, populations within reserves can mature without intervention. Larger and older individuals, which supply the majority of eggs, are able to reproduce supplying eggs and larvae dispersed by ocean currents to both reserves and surrounding fished areas (Fig. 1). Reserves are unlikely to provide much protection for highly migratory species; these would benefit only in proportion to the time they remain in a protected area.

Substantial evidence supports the primary assumption that depleted demersal populations in protected areas will regenerate (Randall, 1982; White, 1986, 1988; Bohnsack et al., 1989; Davis, 1989; Roberts and Polunin, 1991, 1993; Bohnsack, 1993, 1996; Dugan and Davis, 1993; Towns and Ballantine, 1993; Jones, 1994; Roberts and Polunin, 1994; Rowley, 1994). Examples include spiny lobster (Panulirus argus) in the Dry Tortugas, Florida (Davis, 1977); rock lobster (Jasus edwardsii) in New Zealand (Cole et al., 1990); and reef fishes in the Florida Keys (Bohnsack, 1982; Clark et al., 1989; PDT 1990); Australia (Beinssen, 1988); Belize (Roberts and Polunin, 1994); and Hawaii (Billig, 1990). Increased abundance and size of some fishes occurred in areas protected from fishing off Kenya (McClanahan and Muthiga, 1988; McClanahan and Shafir, 1990), South Africa (Bennett and Attwood, 1991), and New Zealand (Cole et al., 1990; Towns and Ballantine, 1993). Reserves have also been shown to export fishes to surrounding areas in Florida (Funicelli et al., 1988), Hawaii (Holland et al., 1993), and South Africa (Attwood and Bennett, 1994), and have been responsible for maintaining fisheries in the Philippines (Alcala, 1988; Alcala and Russ, 1990; Russ and Alcala, 1994) and Japan (Yamasaki and Kuwahara, 1990).

Fishes that occasionally wander out of the reserves can support traditional and trophy fisheries. Reserves to some extent reduce long-term data collection needs, and management can operate without complete information about each species and their interactions. Several modeling efforts 
have shown that potentially greater fish abundance and availability would more than compensate for the increased human competition caused by displaced fishermen moving to open areas ( $\mathrm{Po}_{\mathrm{O}-}$ lacheck. 1990; DeMartini, 1993; Bohnsack. 1994: Man et al., 1995).

Marine reserves address many issues that often are not adequately treated by traditional management approaches (Davis, 1989; PDT, 1990). Not only is recruitment overfishing ameliorated, but serial overfishing is treated by eliminating bycatch of particularly rare and vulnerable species. Incidental bycatch mortality is eliminated because tishes are never caught or handled. Protected from fisheries selection, genotypes retain their natural advantages within reserves and can be dispersed to the surrounding population by natural processes, thus preventing genetic alteration.

Reserves also allow scientific education and ecotourism activities impossible in fished areas. By creating reference areas with minimal human impact. managers are better able to distinguish between short- and long-term natural changes, and those changes caused by human actions (Polovina, 1994). Reserves can be used to improve public awareness and understanding of natural systems and human impacts on those systems. Reserves can simplify compliance and enforcement; it is usually easier to determine whether someone is fishing than to determine whether they are using legal methods or have a legal catch. Also, limited education and enforcement resources can be more effectively focused in restricted critical areas.

One of the most important functions of reserves is to provide insurance against stock collapse. By protecting some resources until a full understanding of the effects of exploitation can be determined, the risk of recruitment failure is reduced. Management designed for "average" conditions may not adequately respond to extreme or highly variable conditions. Because fishing tends to selectively remove larger and older animals and reduce total reproductive output. exploited stocks become more vulnerable to recruitment failure with subtle increases in natural environmental variation. If a stock collapses. for whatever reasons. fishery reserves can act as a reservoir for rebuilding a stock at a rate faster than would otherwise be possible.

The idea of periodically opening up reserves to "pulse" fishing is often suggested, and may be practical only for short-lived. fast growing species. This strategy is probably untenable for many long-lived species for two reasons. First. because the period closed to fishing would have to last many years for species that live for decades (Bohnsack, 1994); and second. because the benefits accrued from protection would be rapidly dissipated. For example, when recreational divers in the Dry Tortugas, Florida, were limited to only two hand-caught spiny lobster per person per day, after only 8 mon catch rates were reduced to $58 \%$ of the preharvest levels (Davis, 1977: Davis and Dodrill, 1980). After the reopening to recreational tishing of an Australian reef closed for $3.5 \mathrm{y}$. $\sim 25 \%$ of the grouper were caught in only $2 \mathrm{wk}$ (Beinssen, 1988). Within a year of discovering a new reef off North Carolina, $80 \%$ of the biomass of snowy grouper. Epinephelus niveatus, was removed (Epperly and Dodrill, 1995). Similar results have been well documented in the Philippines (Alcala, 1988: Alcala and Russ, 1990: Russ and Alcala. 1994).

Research is needed to determine the ideal size. number, total area, and location of reserves to achieve specific management goals. Site selection will require integrating knowledge from many scientific disciplines including oceanography, computer science. system analysis, fisheries, ecology, social science, and resource management. Reserves should support a reproductive population with sufficient spawning potential to recolonize critical habitats and encompass a wide variety of habitats, including nursery areas and adult habitats. Sites must include a mosaic of representative or essential features (Pressey et al., 1993). Locations should consider key oceanographic processes (Carr and Reed, 1993), economic and social factors (Tisdell and Broadus, 1989), and home range size, habitat requirements and larval dispersal distances (Quinn et al., 1993). Protecting small strategically located source areas that are net exporters of individuals could be most effective (Pulliam, 1988). Several reviews have recommended reserve networks with strategically placed, isolated areas containing connected metapopulations (e.g.. Soulé and Simberloff, 1986: Simberloff, 1988; Dyer and Holland, 1991; Towns and Ballantine, 1993: Ballantine. 1995).

\section{Application to the Florida Keys National Marine Sanctuary}

The Florida Keys are a national treasure supporting rich subtropical multispecies reef fisheries, a multibillion dollar tourist economy, and unique aesthetic qualities. Varied habitats include estuaries, barrier islands. and coral reefs that support high species diversity. Concern about human disturbance of the Keys ecosystem resulted in the 1990 establishment of the Florida Keys National Marine Sanctuary (FKNMS) (DOC. 1995). Although marine reserves in the FKNMS will encompass $<6 \%$ of the total $2.800 \mathrm{na} \mathrm{mi}^{2}$. they are an essential part of the proposed management plan (DOC. 1995) (Fig. 2). Proposed reserves include three large "Replenishment Reserves" and 19 much smaller "Sanctuary Preservation Areas" (SPAs). Replenishment reserves are bands, several miles wide, from shore to deeper waters and include representative habitats spread longitudinally at the upper, middle, and lower portions of the Sanctuary. SPAs each cover a few thousand square meters of sensitive forereef habitat. Replenishment
$\mathrm{M}$

address many issues

that often are not

adequately treated by

traditional manage-

ment approaches. 


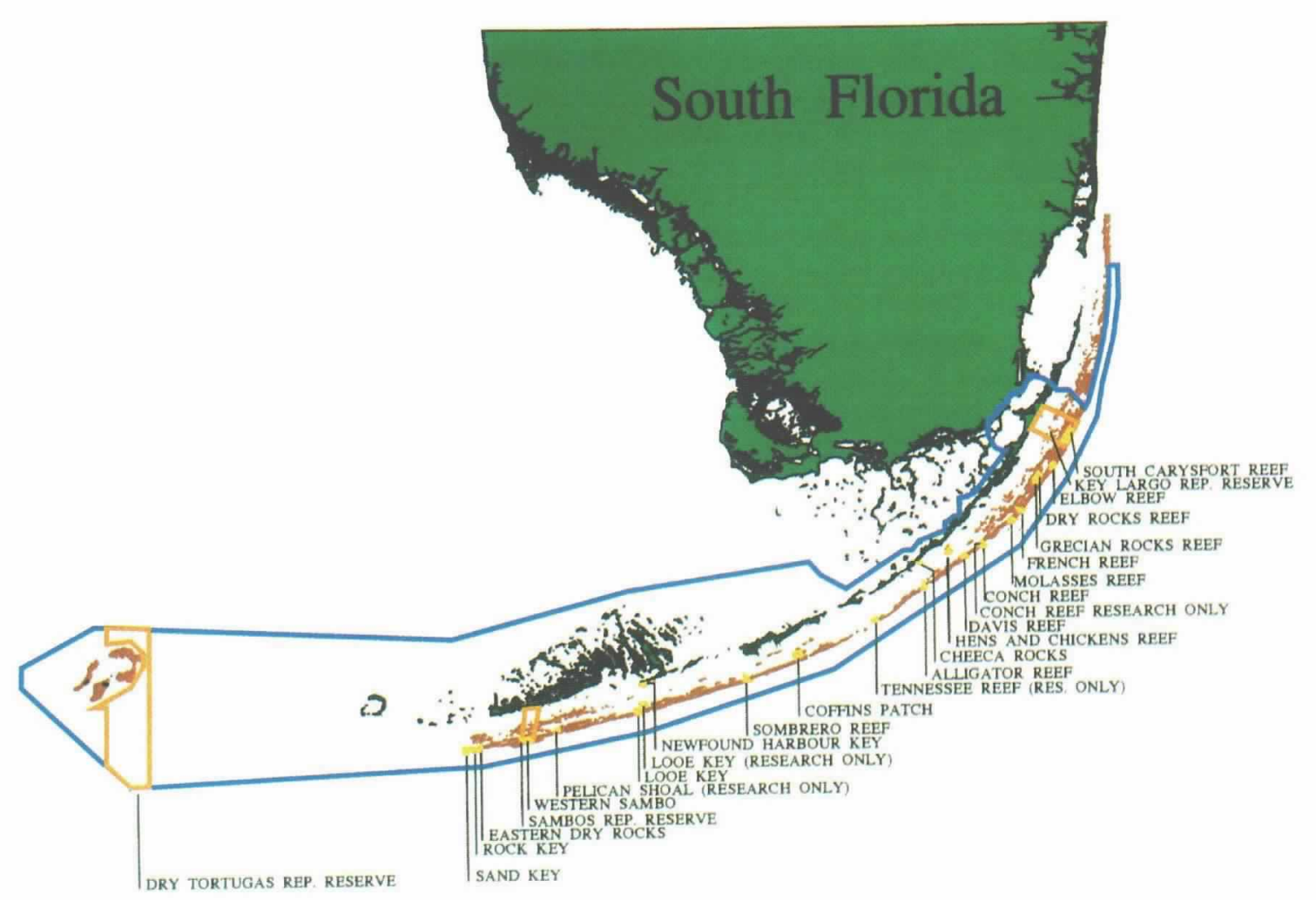

Fig. 2: Map of the Florida Keys National Marine Sanctuary area (blue boundary) showing locations of the proposed larger replenishment reserves (orange bounded areas) and sanctuary protection areas (yellow bounded areas) along the coral reef tract (red).

\section{The Florida Keys}

are a national trea-

\section{sure supporting rich}

subtropical multi-

species reef fisheries,

a multibillion dollar

tourist economy, and

unique aesthetic qualities. reserves have greater potential for protecting biodiversity because of their size and coverage.

Site selections were supported by University of Miami SEFCAR (Southeast Florida and Caribbean Recruitment Project) research, augmented by an ongoing 17-y reef fish survey conducted by NMFS. Sites were positioned to take advantage of oceanographic processes that favor larval dispersal and recruitment (Lee et al., 1992, 1994; Cha et al., 1994; Limouzy-Paris et al., 1994) (Fig. 2); the largest zone being placed most upcurrent in potential source areas and the second largest being placed in recipient areas with the highest concentration of reefs and the greatest biodiversity.

Populations of Caribbean species are believed to be connected through basin-wide egg and larval dispersal. If so, some countries may be able to deplete their stocks with little perceptible impact on local recruitment. Also, there is little incentive for local conservation because population resupply will likely continue from upcurrent sources, even though local overexploitation may cause downcurrent recruitment to decrease. Thus Florida Keys fishers believe local conservation is relatively unimportant because locally produced larvae will be swept away by the Florida Current. Although this may be partially true for some species that have planktonic larvae of exceptionally long duration, such as spiny lobster (but see Lee et al., 1994), recent studies show that currents and the
Tortugas and Pourtales gyres can also retain larvae for considerable periods of time to resupply local reef fish populations in the Florida Keys (Lee et al., 1992, 1994; Porch, 1993) (Fig. 3).

Marine reserves in the FKNMS present a unique opportunity to study the relative impacts of fisheries exploitation and oceanographic processes in determining biodiversity and the abundance of reef populations because zones provide different treatments (protected, partially protected, and unprotected) in replicated sites of large and small sizes. The research goal in the FKNMS is to provide a scientific basis for assessing the effectiveness of marine reserves as focal management tools for coastal ecosystem management. Our objective is to develop new methods for quantitative assessment of reef fish community composition and abundance over time. The null hypothesis is that no change will occur in populations or communities inside or outside protected zones. We will quantitatively assess present conditions and changes in the reserves and surrounding fished areas using visual survey sampling methods employed since 1979 (Fig. 4). To efficiently analyze the data, we have employed innovations in survey design aided by recent advances in computer technology (Rothschild et al., 1996). We expect that there will be significant changes in protected areas compared with surrounding less-protected areas; some significant changes may occur in as little as 2-5 y (Bohnsack, 1982). 
A cornerstone for our work is scientific data visualization - the use of sophisticated computer graphics to gain insight and understanding into complex problems characterized by large data sets. A key role of visualization is that one can identify candidate coupling and forcing factors without having to regrid data. Visualization provides a means to assess the data and implied couplings, before statistical testing, and aid in the formulation of quantitative model structure that could not otherwise be readily identified. With this technology we hope to better understand ecosystem process and test various hypotheses regarding the efficacy of marine reserves. For example, we would like to view and predict the transport and fate of larvae generated from spawning aggregation (Fig. 5). We also hope to clarify the relative impacts of fisheries exploitation and oceanographic processes in determining reef biodiversity and abundance of reef resources.

We are testing several critical hypotheses about resource changes in space and time in cooperative research involving the University of Miami, the U.S. Man and the Biosphere Program, the FKNMS, and the Southeast Fisheries Science Center of the National Marine Fisheries Service of NOAA:

- $\mathrm{H}_{\mathrm{ol}}$ : Abundance, average individual size, and spawning potential of exploited species will increase within reserves. For reserves to be effec-

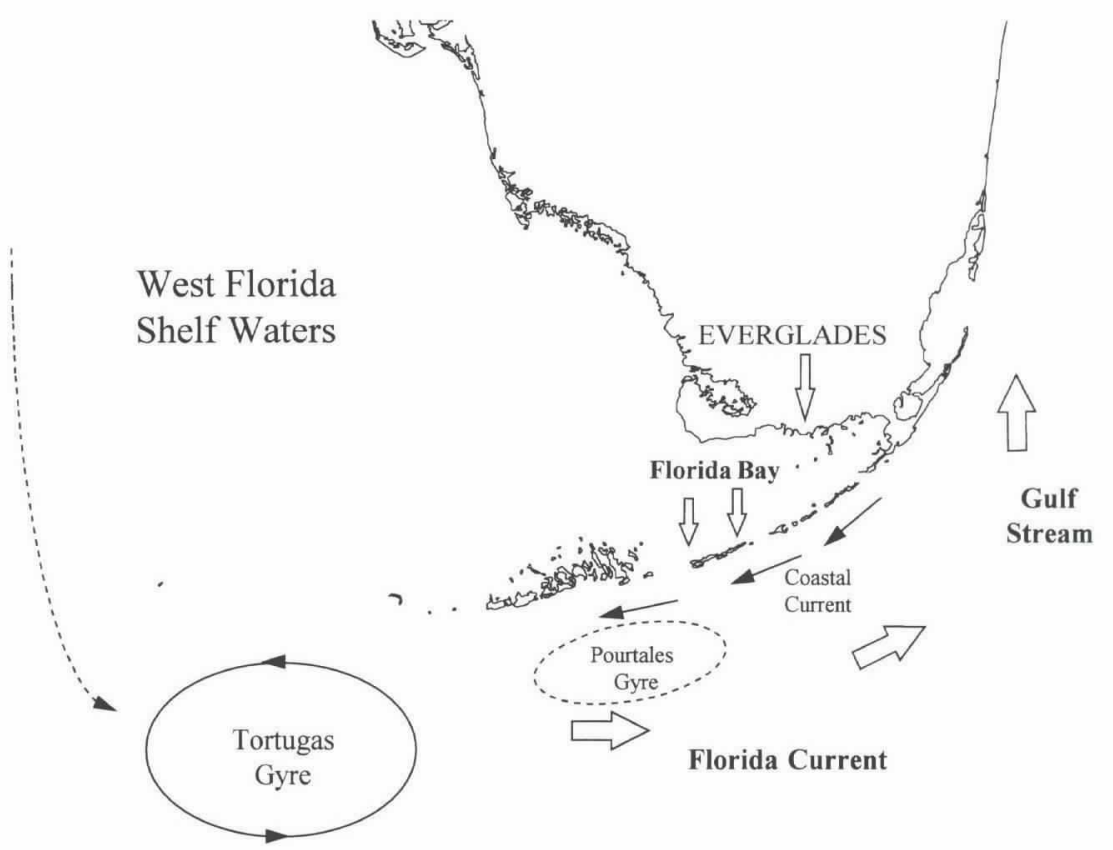

Fig. 3: Dominant current patterns of the South Florida regional ecosystem and Florida Keys showing the Florida Current, Gulf Stream, and Tortugas and Pourtales gyres.

tive, it is necessary that reserves increase spawning potential and protect biodiversity. Spawning potential can be increased by increasing population abundance and size structure

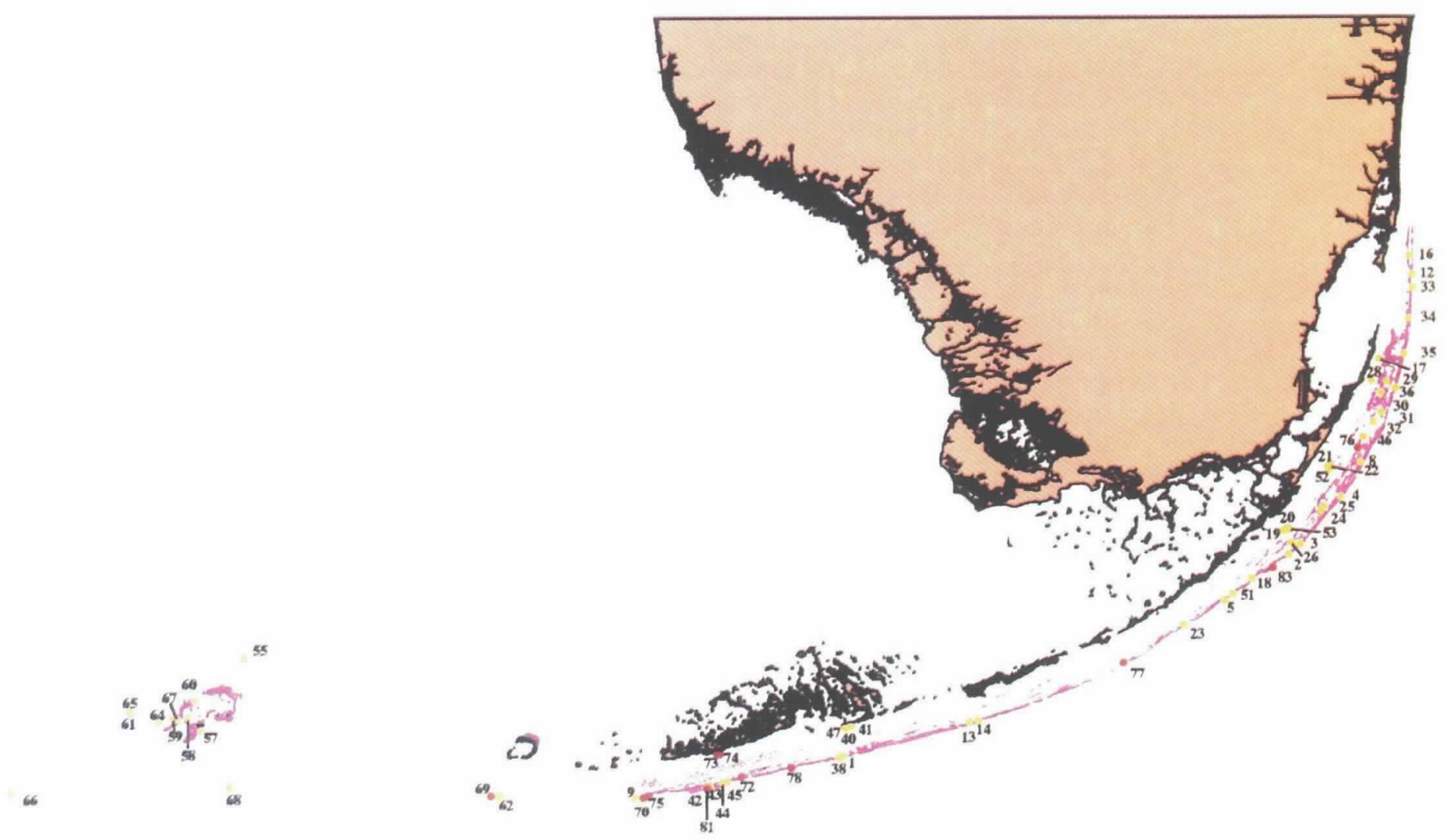

Fig. 4: Distribution of fishery-independent research sampling sites for reef fish visual surveys conducted in the FKNMS area from 1979 to 1995. Coral reef tract is shown in red. 


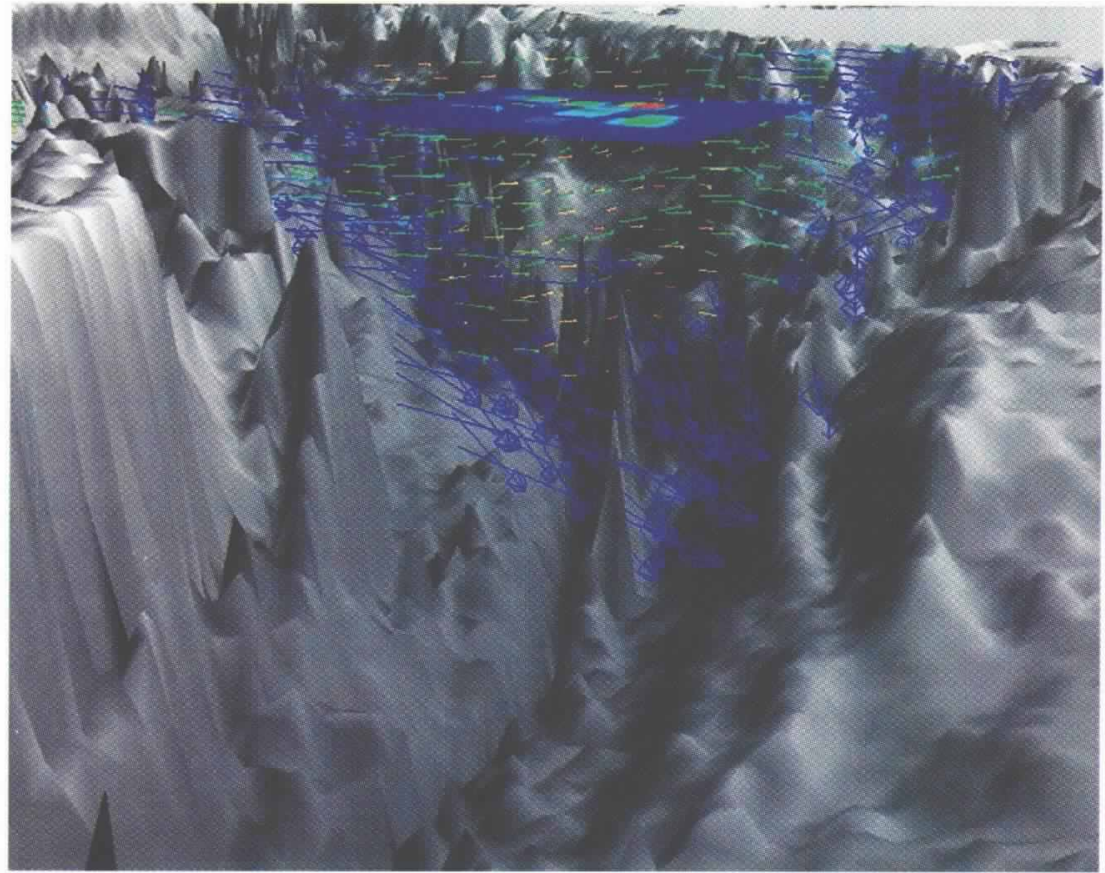

Fig. 5: A fish-eye view of the transport-and-fate of a "spawning slick" of larvae generated from an aggregation of sexually mature grouper as it is influenced by advection from hydrodynamic current patterns. Slick density is highest at red and lowest at dark blue. Arrows indicate current direct and speed.

\section{There is a clear}

need to . . . change

from single species

management to

ecosystem manage-

ment to protect

marine biodiversity

and promote sustain-

able use. through differential mortality inside versus outside reserves. We predict that the greatest proportional population increases will be among the more heavily exploited species and those species with sedentary adults. No changes in population abundance or size structure would falsify this hypothesis.

- $\mathrm{H}_{\mathrm{o} 2}$ : Biological changes and biodiversity will be correlated with the level of protection. We predict that the magnitude of biological changes and biodiversity will decrease in the following order: no human access, no harvest activities, partial protection from certain harvest activities, and open access to all activities (based on current state and federal fisheries regulations). No changes or a lack of a correlation with the protection levels would falsify this hypothesis.

- $\mathrm{H}_{\mathrm{o} 3}$ : Reserve size is important. We predict that larger species and those species with greater areas of activity will require larger protected areas. This hypothesis will be tested by monitoring population responses of various species to different sized reserves. Results will help managers predict what minimum size is necessary to be effective for species with specific biological characteristics. These predictions can be falsified by data showing no correlations in fish density for larger species with the amount of protected area.

- $\mathrm{H}_{\mathrm{o} 4}$ : Reserve location is important. We predict that in addition to size, zone effectiveness will be influenced by habitat quality, distribution, quantity, and proximity of nursery habitats. These predictions will be tested using habitat data collected independently through the Nature Conservancy by the Florida and Caribbean Marine Conservation Science Center at the University of Miami.

\section{Conclusions}

At a time when diversity of oceanic fishes is threatened, fishery management can no longer strive simply to maximize yield while ignoring biological interactions, the physical and biological environments, and impacts of fishing gears and catches on habitat and biodiversity. There is a clear need to improve monitoring methods and change from single species management to ecosystem management to protect marine biodiversity and promote sustainable use. Research and education are essential to increase public appreciation of biodiversity and the impacts of human activities. Both resource managers and users need to develop realistic expectations and a risk-averse philosophy toward resource exploitation and management effectiveness. To be effective, decision makers must maintain a systems view of the resources. Proposed marine reserves in the Florida Keys present a unique research opportunity to clarify the relative impacts of fisheries exploitation and oceanographic processes in determining reef biodiversity and abundance of reef resources.

\section{Acknowledgements}

This research was sponsored by NOAA and the U.S. Man and the Biosphere Program Marine and Coastal Ecosystem Directorate (4710-142-L3-B). We thank the NOAA Cooperative Institute for Marine and Atmospheric Studies at the University of Miami for logistical support. C. Rivero, R. Kulkarni and G. Diaz assisted with graphics.

\section{References}

Alcala, A.C., 1988: Effects of marine reserves on coral fish abundance and yields of Philippine coral reefs. Ambio, 17. 194-199.

- and G.R. Russ, 1990: A direct test of the effects of protective management on abundance and yield of tropica marine resources. J. Cons. Int. Explor. Mer., 46, 40-47.

Attwood, C.G. and B.A. Bennett, 1994: Variation in dispersa of Galjoen (Coracinus capensis) (Teleostei: Coracinidae) from a marine reserve. Can. J. Fish. Aquat. Sci., 51, 1247-1257.

Ault, J.S. and D.B. Olson, 1996: A multicohort stock production model. Trans. Amer. Fish. Soc. 125, 343-363

Ballantine, W.J., 1995: Networks of "no-take" marine reserves are practical and necessary. In: Marine Protected Areas and Sustainable Fisheries. N.L. Shackell and J.H.M Willison, eds. Science and Management of Protected Areas Association. Wolfville, Nova Scotia, Canada, 13-20.

Bannerot, S.P., W.W. Fox, Jr. and J.E. Powers, 1987: Reproductive strategies and the management of snappers and groupers in the Gulf of Mexico and Caribbean. In: Tropical Snappers and Groupers: Biology and Fisheries Management. J.J. Polovina and S. Ralston, eds. Westview Press, Boulder, 659 pp., 561-604.

Beinssen, K., 1988: Boult Reef revisited. Reflections. GBRMPA. March 1988, 8-9. 
Bennett. B.A. and C.G. Attwood, 1991: Evidence for recovery of a surf-zone fish assemblage following the establishment of a marine reserve on the southern coast of South Africal. Mar. Eocol. Prog. Ser., 75. 173-181.

Bergh. M.O. and W.M. Getz, 1989: Stability and harvesting of competing populations with genetic variation in life history strategy. Therr. Popul. Biol.. 36, 77-124.

Billig, P.. 199(): Hanauma Bay's ecology geth a boost from $\mathrm{UH}$ Sea Grant education program. University of Hawail Seal Grant College Program. Makcii, 12, 1-2.

Bohnsack, J.A. 1982: The effects of piscivorous predator removal on coral reef fish community structure. 1981 Gutshop: Third Pacifo Technical Werkshop Fish Food Hubits Studies. Washington Sea Grant Publication. $258-267$

1993: Marine reserves: they enhance fisheries. reduce conflicts, and protect resources. Oceanus, 36, 63-71.

1994: How marine fishery reserves can improw reef fisheries. Proc. Gulf Caribh. Fish. Inst., 43. 217-241

1996: Maintenance and recovery of fishery productivity. In: Tropical Rect Fishcrics. N.V.C. Polunin and C.M. Roberts, eds. Chapman and Hall, chapt. 11

H. Kumpt. E. Hobson, G. Huntsman. K.W. Able and S.V. Ralston, 1989: Report on the concept of Marine Wildeness. Fisherie's, 14. 22-24

Carr. M.H. and D.C, Reed. 1993: Conceptual issues relevant to marine harvest refuges: examples from temperate reel tishes. Can. J. Fish. Aquat. Sci., 50. 2019-2028.

Cha, S.S., M.F. McGow'an and W.J. Richards, 1994: Vertical distribution of tish larvae off the Florida Keys. 26 May-5 June 1989. Bull. Mar. Sci. 53. 828-842.

Clark, J.R.. B. Causey and J.A. Bohnsack, 1989: Benefits from coral reef protection: Looe Key. Florida. Coastal Zone 89: Proceedings th Symposium on Coastal and Ocean Management. 4, 3076-3086

Cole, R.G. T.M. Ayling and R.G. Creese, 1990: Effects of marine rescrve protection at Goat lsland, northern New Zealand. N. Z. J. Mar. Freshuater Re's., 27, 197-210.

Davis. G.E., 1977: Effects of recreational harvest on a spiny lobster. Panulirus argus, population. Bull. Mar. Sar. 27. 223-236.

1989: Designated harvest refugia: the next stage of marine fishery management in California. CalCOFI Rep., 30, 53-58.

and J.W. Dodrill, 1980: Marine parks and sanctuaries for spiny lobster tisheries management. Proc: Gult Caribl. Fish. Inst., 32. 19ł-207.

DeMartini, E.E. 1993: Modeling the potential of tishery re serves for managing Pacific coral reef tishes. Fish. Bull.. U.S., 9I, $414+27$.

DOC (Department of Commerce. U.S.), 1995: Florida Kevs National Marine Sanctuary Draft Management Plan/Environmental Impact Statement. UI.S. Department of Commerce. NOAA, Washington. DC.

Doherty. P.J. and D.M. Williams, 1988: The replenishment of coral reef fish populations. Oceanogr. Mar. Bisl. Annu. Re'.., 26, 487-551.

Dugan, J.E. and Davis. G.F.. 1993: Applications of marine refugia to coastal tisherics management. Can. J. Fish Acquat. Si.i, 50, 2029-2()+2.

Dyer, M.I. and Holland. M.M.. 1991: The biosphere-reserse concept: needs for a network design. Binscicnce', 41 , 319-324.

Epperly. S.P. and J.W. Dodrill. 1995: Catch rates of snowy grouper Epinephelus niveatus, on the deep reets of Onslow Bay. Southeastern U.S.A. Bull. Mar. Sit. .56. $4.50-461$

Funicelli, N.A.. D.R. Johnson and D.A. Meinehe, 1988: Assessment of the effectiveness of an existing tish sanctuary within the Kennedy Space Center. Special Purpose Report on the Marine Fisheries Commission of Floruda. $5+\mathrm{pp}$.
Goodyear, C.P. 1989: Spawning stock biomass per recruit: the biological hasis for a fisheries management tool. ICCAT Working Document SCRS/89/82, $10 \mathrm{pp}$.

Grimes, C.B., 1987: Reproductive biology of the Lutjanidae: a review. In: Tropical Snappers and Groupers: Biology and Fisheries Management. J.J. Polovina and S. Ralston. eds. Westview Press, Boulder. 659 pp. 239-294.

Hardin. G., 1968: The tragedy of the commons. Scicnce. 162, $1243-1248$

Holland. K.N., J.D. Peterson, C.G. Lowe and B.M. Wetherbee. 1993: Movements. distribution. and growth rates of the white goatlish Mulloides flavoline atus in a fisheries conservation zone. Bull. Mar. Sit., 52, 982-992.

Hughes. T.P., 1990): Recruitment limitation, mortality, and population regulation in open systems: a case study. Ecologi: 7I, 12-20)

Hughes. R.M. and R.F. Noss, 1992: Biological diversity and biological integrity: current concerns for lakes and streams. Fisheries, 17, 11-17.

Huntsman, G.R., 1994: Endangered marine fintish: neglected resnurces or beasts of tiction? Fisheries. 19.8-15.

Hutchings, J.A. and R.A. Myers, 1994: What can be learned from the collapse of a renewable resource? Atlantic cod. Gadas morhua, of Newfoundland and Labrador. Can. J. Fish. Aquat. Sci, 51, 2126-2145.

Jones, P.J.S. 199.4: A review and analysis of the objectives of marine nature reserves. Ocean \& Coast. Manage. 24. $149-178$.

Knauss. J.A. 1992: The state of the world's marine resources. In: The State of the World's Fighcries Resources: Proceedings of the World Fisheries Congress, Plinary Sessions. C.W. Voigtlander. cd. Oxford \& IBH, PVT. LTD., New Delhi, chapt. 3, 19-24.

Lee, T.M. C. Rooth. E. Williams, M. McGowan, A.F. Szmant and M.E. Clatke. 1992: Influence of Florida Current, gyres and wind-driven circulation on transport of larvae and recruitment in the Florida Keys coral reefs. Comt. Sholf Res.s. 12,971-1002.

M.E. Clarke. E. Williams, A.F. Szmant and T. Berger. 1994: Fvolution of the Tortugas gyre and its influence on recruitment in the Florida Keys. Bull. Mar. Sci., 54 . $621-6+6$.

Limouzy-Paris, C.. M.F. McGowan. W.J. Richards, J.P. Umaran and S.S. Cha. 1994: Diversity of fish larvae in the Flurida Kcys: results from SEFCAR. Bull. Mar. Sci., 5f, 857-870

Ludwig. D.. R. Hilborn and C. Walters. 1993: Uncertainty, resource exploitation, and conservation: lessons from history. Scichece, 260), 17-18.

Man, A.. R. Latw and N.V.C. Polunin. 1995: Role of marine reserves in recruitment to reef tisheries: a metapopulation model. Bisl. Consern., 71, 197-204.

McClanahan. T.R.. 1989: Viewpoint: are conservationists fish bigots"' Bioscie'nce, $f 0,2$

and N.A. Muthiga. 1988: Changes in Kenyan coral reef community structure and function due to exploitation. Hydrohiologia, 166, 269-276. and S.H. Shatir, 1990: Causes and conmequences of sca urchin abundance and diversity in Kenyan coral reef la groons. Oecologia, 83, 362-370).

Munro. J.L. and D.M. Williams. 1985: Assessment and management of coral reef fisheries: Biological, environmental. and socio-economic aspects. Prese. Fifth Interm. Corral Rect Congress. Tahiti, 4, 541-578.

Murphy. G.I.. 1968: Pattern in life history and the envirnnment. Am. Nal., 102, 391- 403 .

National Research Council (U.S.) Committee on Fisheries. 1994: Improving the management of U.S. marine tisheries. Nutional Academy Press. Washington, DC, $62 \mathrm{pp}$.

Neluon. K. and M. Soulé, 1987: Genetical conservation of exploited fishes. In: Population Genetics \& Fishery Management. N. Ryman and F. Utter, eds. Liniversity of 
Washington Press. London, 420 pp., 345-369.

Norse, E.A., ed., 1993: Global marine biological diversity: a strategy for building conservation into decision making. Island Press, Washington, DC, 384 pp.

Öhman. M.C.. A. Rajasuriya and O. Lindén. 1993: Human disturbances on coral reefs in Sri Lanka: a case study. Ambio, 22. 474-480.

PDT, 1990: The potential of marine fishery reserves for reef fish management in the U.S. southern Atlantic. SnapperGrouper Plan Development Tcam Report for the South Atlantic Fishery Management Council (J.A. Bohnsack. Subcommittee Chair). NOAA Technical Memorandum NMFS-SEFC-261, 45 pp.

Polacheck, T., 1990: Year around closed areas as a management tool. Nat. Resource Modeling, 4, 327-354

Polovina, J.. 1994: The case of the missing lobsters. Nat. Hist., $103,50-59$.

Porch. C.E.. III, 1993: A numerical study of larval retention in the southern Straits of Florida. Ph.D. dissertation, University of Miami. Coral Gables, FL, $245 \mathrm{pp}$.

Pressey, R.L., C.J. Humphries, C.R. Margules, R.I. VaneWright and P.H. Williams, 1993: Beyond opportunism: key principles for systematic reserve selection. TREE. 8 , $124-128$.

Pulliam, H.R.. 1988: Sources, sinks, and population regulation. Am. Nat., 132, 652-661.

Quinn. J.F.. S.R. Wing and L.W. Botsford, 1993: Harvest refugia in marine invertebrate fisheries: models and applications to the red sea urchin Strongylocentrotus franciscanus. Am. Zool., 33, 537-550.

Randall, J.E., 1982: Tropical marine sanctuaries and their significance in reef fisheries research. In: The Biological Bases for Reef Fishery Management. G.R. Huntsman. W.R. Nicholson and W.W. Fox. Jr., eds. NOAA Tech. Memorandum NMFS-SEFC-80. $216 \mathrm{pp}$.

Roberts, C.M. and N.V.C. Polunin. 1991: Are marine reserves effective in management of reef fisheries? Rev: Fish Biol. Fish. 1. 65-91.

and N.V.C. Polunin, 1993: Marine reserves: simple solutions to managing complex fisheries? Ambio, 22. $363-368$.

and N.V.C. Polunin, 1994: Hol Chan: demonstrating that marine reserves can be remarkably effective. Coral Reefs, 13,90.

Rosenberg, A.A., M.J. Fogarty. M.P. Sissenwine, J.R. Beddington and J.G. Shepherd. 1993: Achieving sustainable use of renewable resources. Science, 262, 828-829.

Rothschild, B.J.. 1986: Dynamics of Marine Fish Populations. Harvard University Press, Cambridge, MA.

J.S. Ault, P. Goulletquer and M. Héral, 1994: Decline of the Chesapeake Bay oyster population: a century of habitat destruction and overfishing. Mar. Ecol. Prog. Ser. 111. 29-39.

J.S. Ault and S.G. Sinith, 1996: A systems science approach to fisheries stock assessment and management.
In: Stock Assessment: Quantitative Methods and Applications for Small-Scale Fisheries, V.F. Gallucci, S. Saila. D. Gustafson and B.J. Rothschild, eds. Lewis Publishers (Division of CRC Press). New York, chapt. 9. 473-492.

Rowley, R.J., 1994: Case studies and reviews: marine reserves in fisheries management. Aquat. Cons. Mar. Freshwater Ecosystems, 4. 233-254.

Russ, G.R. and A.C. Alcala, 1994: Sumilon Island Reserve: 20 years of hopes and frustration. NAGA: The ICLARM Quarterly, 17, 8-12.

Sale, P.F., 1980: The ecology of fishes on coral reefs. Oceanogr. Mar. Biol. Anmu. Re1., 18, 367-421.

(ed.) 1991: The Ecology of Fishes on Coral Reefs. Academic Press, San Diego. CA, 754 pp.

Simberloff, D., 1988: The contribution of population and community biology to conservation science. Annu. Rev. Ecol. Syst. 19, 473-511.

Soulé, M.E. and D. Simberloff, 1986: What do genetics and ecology tell us about design of nature reserves? Biol. Conserv. 35, 19-40.

Thompson. R. and J.L. Munro, 1974: The biology, ecology and bionomics of Caribbean reef fishes: Serranidae (hinds and groupers). In: Caribbean Coral Reef Fishery Resources. J.L. Munro, ed. ICLARM Stud. Rev. 7, 58-81.

Tisdell, C. and J.M. Broadus, 1989: Policy issues related to the establishment and management of marine reserves. Coastal Manage., 17, 37-53.

Towns, D.R. and W.J. Ballantine, 1993: Conservation and restoration of New Zealand island ecosystems. Trends Ecol. Evol, \&, 452-457.

Underwood. A.J. and P.G. Fairweather, 1989: Supply-side ecology and benthic marine assemblages. Trends Ecol. Evol. 4. 16-20.

Upton, H.F., 1992: Biodiversity and conservation of the marine environment. Fisheries, 17, 20-25.

Waters. J.R., 1991: Restricted access vs. open access methods of management: toward more effective regulation of fishing effort. Mar. Fish. Rev., 53, 1-10.

White, A.T., 1986: Marine reserves: how effective as management strategies for Philippine, Indonesian and Malaysian coral reef environments? Ocean Manage., 10 , $137-159$.

White, T.T., 1988: Marine Parks and Reserves: Management for coastal environments in Southeast Asia. ICLARM Education Series 2. International Center for Living Aquatic Resources Management, Manila. Philippines. $36 \mathrm{pp}$.

Yamasaki. A. and A. Kuwahara, 1990: Preserved area to effect recovery of overfished Zuwai crab stocks off Kyoto Prefecture. In: Proceedings of the International Symposium on King and Tanner Crabs. Alaska Sea Grant College Program. University of Alaska, Fairbanks, Alaska, 575-578. 